\title{
ENVIRONMENTAL ASPECTS OF THE PRODUCTION OF FOOD PRODUCTS
}

\author{
D. Ruscheva* \\ Department "Regional and Sectoral Economy", Economic Research Institute \\ Bulgarian Academy of Sciences, Sofia, Bulgaria
}

\begin{abstract}
The purpose of the report is to assess the main environmental aspects of the food products industry in Bulgaria. It focuses on the quantitative dimensions of food products and the opportunities for satisfying their consumption in the country; observance of ecological requirements during the production process, at the entrance and at its exit, as well as in the other units of the food chain: production-storage-transportrealization-consumption. The main result of the study is to outline problems and justify their causes. The conclusions are in the context of national food security, enhancing the competitiveness of the food products, protecting the environment and improving the quality of life and the agricultural policy pursued in the country.
\end{abstract}

Key words: environmental requirements, food chain, national food security, agricultural policy.

\section{INTRODUCTION}

The production of food products in Bulgaria is important because it is a source of raw materials for the processing industry, consumption and export resources. Its quantitative parameters determine the possibilities for meeting the food needs of the population and ensuring national food security. The production of food products should be carried out in such a way as to provide the necessary quantities of them to produce quality products and on the other hand to comply with basic ecological requirements at the entrance of the food products and the technological processing of the raw materials and their output, protecting the environment for future generations. A cumulative effect is only obtained when environmental requirements are strictly observed not only in the production but also in the food chain: storage-transportationrealization-consumption. The quantitative and qualitative dimensions of the production of food products are important for national food security.

\footnotetext{
*Correspondence to: Darina Ruscheva, Department "Regional and Sectoral Economy", Economic Research Institute, Bulgarian Academy of Sciences, 3 Aksakov Str., Sofia, E-mail: darinar@abv.bg
}

\section{EXPOSITION DIMENSIONS AND TRENDS}

Over the last decade, in the context of Bulgaria's membership of the European Union and in connection with the new requirements of the EU Common Agricultural Policy (CAP), the environment in which the production of food products takes place is changing. A study was conducted on 33 food products produced in: agriculture (plant growing - 17 and livestock - 3) and in the food industry - 13 . Comparing the quantitative dimension of food production in 2016 with those at the beginning of membership of Bulgaria in the EU - 2007 allows the following summaries to be made:

- $\quad$ Of the 17 products in plant growing at $11(64.7 \%)$, production is increasing - most in the cereals and in the sunflower. A positive assessment deserves the growth of fruit production (apples - by $71 \%$, apricots - by $86.7 \%$, cherries and plums - more than 2 times). Production of the remaining $6(35,3 \%)$ crops is decreasing in the following order: beans $-35,1 \%$, potatoes $-42,6 \%$, wine grapes $58,4 \%$, table grapes $-74,3 \%-85.0 \%$ and pepper $-88.1 \%$. The main reason is to reduce the area occupied by these crops. It varies from $37.5 \%$ of 2007 in potatoes to $63.6 \%$ in peppers. 
- Reduces meat production in carcass weight, excluding meat by-products $(90,1 \%)$, milk $(86.5 \%)$ and eggs $(84.3 \%)$. The reason is above all to reduce the number of farm animals in all species - from $92.6 \%$ in cattle to $47.9 \%$ - in goats. An exception is for buffaloes, which are up by $2.1 \%$ compared to 2007 . It should be noted that at the same time there was a decrease in the number of animals in the main flock.

- Regardless of the outlined changes in the quantitative dimensions of production, its internal product structure remains relatively stable, with the leading position for: cereals wheat; vegetables, tomatoes, grapes - wine grapes, meat - poultry meat and milk - cow's milk. Changes in the structure and production of fruit species are due to a decline in the leading position of apples in 2007, with a $38 \%$ share of plums, which in 2016 led the structure by $27.3 \%$. It goes to a more representation of the main fruit species in the structure of production.

- In 7 (53.8\%) of the food products concerned, production is increasing. These are meat, fish and fish products, rice, fresh milk, yoghurt, cheese and oil. In $6(46.1 \%)$ of the products their production decreases: bread and bakery products, meat products, yellow cheese, vegetable cans, fruit mops and sugar and chocolate products. The reduction in 2016 is from $73.9 \%$ (yellow cheese) to $92.6 \%$ (canned vegetables) compared to 2007.

The contraction in production of about half of the main food products produced in agriculture and the food industry in 2016 compared to 2007 highlights important issues related to: - Reduction of raw materials for the processing industry (such as meat, milk, grapes, etc.); restricting resources for domestic consumption (potatoes, beans, pepper, strawberries, etc.) and exports and has a negative impact on national food security. Moreover, it is about agricultural crops for which there are favorable natural and climatic conditions for cultivation, accumulated historical experience in the production of basic food products and the possibilities regarding the amount of their production in the past in the country.

- The occurrence of food deficits. Some of them can be covered by the production in the domestic farms, which is especially important for the people in the villages and small towns of Bulgaria. In the conditions of shrinking production, unemployment and low incomes, it is becoming one of the sources of food consumption of the population. But domestic production should be seen only as an additional source of food. Nowadays, some of the food defects are covered by imports, whereas in the past the object of import was mainly products for which there are no suitable natural conditions for their cultivation in the country. However, the "penetration" of imported products into the Bulgarian food market is related to problems in terms of quality control, undermining the production of small and medium-sized farmers in Bulgaria and others.

\section{DEGREE OF COMMITMENT OF THE PRODUCED AND CONSUMED QUANTITIES OF FOOD PRODUCTS}

It is an interest to assess how the potential of basic food products is lost to satisfying their consumption in Bulgaria at the beginning of its membership in 2007 compared to 2016. For this purpose, the benchmark is calculated as the ratio of the quantities of food products produced and consumed on the basis of the average annual population and the consumption of household products (average per capita). This idea is illustrated on the basis of 20 products: from agriculture - 7 (beans, potatoes, tomatoes, pepper, cucumbers, apples and table grapes) and from the food industry 13 (bread and bakery products, rice, meat, meat fish and fish products, fresh milk, yoghurt, cheese, yellow cheese, oil, canned fruit, canned vegetables and sugar and chocolate products).

In 2007, outlines the following picture. Of the 19 products observed, only 4 (21.0\%) production is over-consumption. These are: yellow cheese (23.5\%), pepper (23.3\%), potatoes $(42.8 \%)$ and sugar and chocolate $(97.3 \%)$ more than their consumption. For the remaining 15 (78.9\%) domestic production in the country can not provide for the satisfaction of the consumption of basic food products. And this non-production is as follows: - 0-10\% - none;

$-11-20 \%$ - Rice;

- 21-30\% - beans and fish and fishery products;

- 31-40\% - fresh milk and apples;

- 41-50\% - none;

- 51-60\% - yoghurt, cheese and table grapes;

- 61-70\% - bread and bakery products;

- 71-80\% - meat and cucumbers;

- 81-90\% - tomatoes and vegetable oil;

$-91-100 \%$ - meat products and vegetable cans.

In 2016, changes in the degree of commitment as a result of changes in the production of basic food products are as follows: - The number of products where production 
exceeds their consumption increases from 4 to $5(26.3 \%)$. Overproduction of meat products (from $92.8 \%$ to $104.9 \%$ ), oil (from $82.9 \%$ to $136.9 \%$ ), canned vegetables (from $91.6 \%$ to $115.1 \%$ ) was overcome; reduces overproduction of sugar and chocolate products (from $197.3 \%$ to $127.1 \%$ ) and increases the production capacity of pepper (from 133, 3\% to $147.5 \%$ ). - In the remaining $14(73.7 \%)$ the production is unable to cover their consumption. And this non-production is the following: - 0-10\% - beans;

$-11-20 \%$ - none;

- 21-30\% - none;

- $31-40 \%$ - fish and fish products;

- 41-50\% - none;

- 51-60\% - fresh milk and apples;

- 61-70\% - bread and bakery products, yoghurt, cheese, table grapes, potatoes;

- 71-80\% - meat and cheese;

- 81-90\% - rice and cucumbers;

$-91-100 \%$ - tomatoes.

A positive trend can appreciate the fact that most of the products manufacturing shrinks though not yet overcome. Especially critical is the situation with beans whose production is within $10 \%$ of the 2007 level, while for potatoes the situation changes from $42.8 \%$ production to more than consumption in 2016, the level of production reaches only $64.9 \%$ of this in 2007.

\section{ENVIRONMENTAL REQUIREMENTS OF THE FOOD CHAIN} Criteria for the quality of food products depend on the assessing subject. For producers, the main criteria are yield and harvest; for processors - the technological characteristics of the food products produced; for traders - the storage of the produce, and for the consumer the taste characteristics and the safety. Quality, including compliance with environmental requirements in the production of food products, is very important because it directly affects the health status of people and is a condition for enhancing the competitiveness of food products in international markets and for environmental protection. At the beginning of the 21st century, these issues became more acute due to the fact that low-quality, low-weight goods are increasingly being offered on the domestic market, with an increased risk to the health of the population due to low safety standards.
The real response to the environmental challenge for agriculture is that more global food production is carried out without substantial increase in the area and with minimal negative impact on the environment. Agricultural policy should treat agriculture not only as an economic sector, but also take into account its functions as a public service provider for environmental preservation, as well as its role in the vitality of rural areas, preservation of cultural heritage, (3). Environmental requirements should be strictly observed throughout the food chain: storagetransportation-realization-consumption.

For plant products is essential soil fertility, rational use of land as an indispensable means of production and the basis for harmonious development of the environment. Bulgaria's land resources for agricultural purposes account for about $55 \%$. Over the past 25 years, it has fallen by $5 \%$, and if this trend continues, they will decline by another 5\% (4) after a quarter of a century. Due to degradation processes (erosion, acidification, salinization, over-wetting, etc.) a part of the soil is irretrievably lost and another - greatly deteriorating its fertility. Some of the soils are unfit for growing crops due to their contamination with chemicals or heavy metals. Part of the arable land is transformed for nonagricultural purposes and others.

Through the water used in the production of food products in agriculture, harmful substances in plants and animals can be introduced into the products and hence in the person who consumes them. Therefore, strict control over its purity is obligatory.

The production of food products largely depends on the purity of the ground layer of the atmosphere. The quality of atmospheric air is determined by the composition and coexistence of its natural ingredients and the added substances of natural and anthropogenic products. It is known that harmful substances cause damage to soil, water and living organisms and lead to adverse effects on human health and ecosystems.

Therefore, soil, water and atmospheric air cleanliness is essential to provide a suitable environment for agrarian production and cleanliness at the entrance. Even to a less extent, this is also true for the food industry. The main environmental requirements for the technologies used in the production of food products in agriculture and the food and drink 
industry are related to the preservation of the quality of the processed raw materials and the production of products that take into account the ecological characteristics.

The environmental requirements for the production of food products of plant origin in agriculture are generally limited to: limitation of soil softening; proper crop rotation; application of modern and quality soil treatment; use of healthy and quality seeds, etc. The negative consequences of the applied technologies in this case can be sought in: demolition of the layer of the soil as a result of the use of inappropriate agricultural machines that drive them; pollution of soil, water and air by means of plant protection chemicals and unused fertilizers, etc.

The environment affects livestock by affecting their senses through food, air, water, and so on. Healthy animals are one of the conditions for the production of quality products. On the other hand, the good health of the animals directly depends on the quality of the feed they feed, the observance of hygienic conditions of the breeding, their protection from diseases, etc. The control over compliance with ecological requirements of the output of the technologies applied in livestock farming is mainly in terms of: timely removal and proper storage of manure; the harmful emissions emitted by air from the building fans, etc.

For the agro-food industry the basic environmental requirements are associated with the use of: quality raw materials in accordance with accepted standards (sugar, fat, etc.); the production of quality products; avoiding environmental pollution. The combination of the technologies used in the food industry and the environment protection is related to: recovery of the waste from the production - the need for the development of a waste management system; use of appropriate packaging and packaging materials, etc. This issue is also important from the point of view of recycling and the environment; control of waste water and gases, etc.

Out of the manufacturing sphere, the issue of complying with environmental requirements is based on their correctness: - storage - in appropriate storage rooms, refrigeration facilities, etc .; - transport - by means of transport facilities, complying with the requirements for less loss of finished products and according to the specifics of the transported produce;
- Trade - the packaging, as well as the material and technical basis of the sales network for the sale of food goods. A big problem is the trade in outdoor goods, in uncontrolled open markets, often near highways and on the street. The health risks of people who bought products from these markets are big and at best end up with poisoning. But, on the other hand, these goods are often cheaper and therefore cheaper to buy. (5).

\section{CONCLUSIONS}

1. Reducing the quantity of basic food products produced in the agriculture and food industry in Bulgaria has a negative impact on national food security.

2. The summary that is required in terms of production capacities to satisfy the consumption of basic food products in Bulgaria, measured by the "degree of commitment" indicator, is that in the last decade only a small product range is taking place. This leads to food shortages and increases the country's dependence on imports. 3. Guarantee for the production and consumption of quality food products from agriculture and the agro-food industry is strict compliance with environmental requirements throughout the food chain. It should not be forgotten that both negatives and positives are increasing by moving from a link to a link in the food chain while products reach consumers. The problem of complying with environmental requirements is complex and complex. The guidelines for its solution should be sought in the creation of:

a) Conditions for overcoming problems of production, technological, organizational, economic, social, etc. a nature that is possible but requires a prolonged period of time;

b) An appropriate environment for reconciling the tasks of production and consumption of food products and the protection of the environment.

4. The production of quality food products helps to increase their competitiveness on domestic and international markets. It is a pledge for a higher health status and improvement of the quality of life of the population in Bulgaria. 5. The agricultural policy implemented in Bulgaria should be aimed at ensuring national food security.

\section{ACKNOWLEDGMENTS}

This work was supported by the Bulgarian Ministry of Education and Science under the National Research Programme „Healthy Foods 
for a Strong Bio-Economy and Quality of Life" approved by DCM \# 577/ 17.08.2018";.

\section{REFERENCES}

1. Statistical Yearbook of Bulgaria.

2. Household budgets in Bulgaria.

3. Popov P., (2016). Aspects of Modern Agricultural Policy of Bulgaria, Journal of Economics and Management of
Agriculture, vol. 2-4, pp. 19-26, ISSN 0205-3845.

4. Teoharov M., (2016). Bulgaria's Soil Resources - Problems and Forecasts, Journal of Agriculture Plus, vol. 9-10, pp. 3-7. ISSN 1310-7992.

5. Ruscheva D., (2000) Food Resources of Bulgaria. Structural and Non-structural Changes, Ed. GorexPress, S., p. 120, ISBN 954-616-059-8. 